\title{
Bioactive potential of Aphanamixis polystachya seed extracts
}

\author{
S. K. Banik ${ }^{1 *}$, S. Iftekhar ${ }^{2}$, A. F. M. M. Rahman' ${ }^{2}$ M. L. Bari ${ }^{3}$ and M. S. Islam ${ }^{1}$ \\ ${ }^{I}$ Institute of Fuel Research and Development, Bangladesh Council of Scientific \& Industrial Research, Dhanmondi, \\ Dhaka-1205, Bangladesh \\ ${ }^{2}$ Department of Applied Chemistry and Chemical Engineering, University of Dhaka, Bangladesh \\ ${ }^{3}$ Center for Advanced Research in Sciences, University of Dhaka, Bangladesh
}

Received: 02 November 2020

Revised: 12 January 2021

Accepted: 31 March 2021

DOI: https://doi.org/10.3329/bjsir.v56i1.54314

\begin{abstract}
Aphanamixis polystachy seed extracts were examined for their in-vitro biological activities. The n-hexane and methanol extract showed significant phenolic content of 12.0 and $11.7 \mathrm{mg} \mathrm{GAE} / \mathrm{g}$, respectively. Antioxidant activity was exhibited by the methanol extract $\left(\mathrm{IC}_{50}: 22.34 \mu \mathrm{g} / \mathrm{mL}\right)$ and moderate activity was shown by the n-hexane extract $\left(\mathrm{IC}_{50}: 63.05 \mu \mathrm{g} / \mathrm{ml}\right)$ compared to $\mathrm{BHT}$ (tert-butyl-1- hydroxy toluene, $\mathrm{IC}_{50}: 14.01 \mu \mathrm{g} / \mathrm{ml}$ ) though both extracts caused moderate clot lysis of $18.84 \%$ and $23.49 \%$ compared to the positive control Streptokinase $(65.16 \%)$. The n-hexane and methanol extract had shown $18.2 \%$ and $32.2 \%$ inhibition of hypnotic solution induced haemolysis respectively, while the $n$-hexane extract had almost no activity $(2.21 \%)$ and methanol extract showed very high (70.17\%) inhibition of heat induced haemolysis compared to acetyl salicylic acid (71.9\%). Sensible and substantial cytotoxicity was exhibited by the $\mathrm{n}$-hexane $\left(\mathrm{LC}_{50}: 13.45 \mu \mathrm{g} / \mathrm{ml}\right)$ and methanol extracts $\left(\mathrm{LC}_{50}: 1.61 \mu \mathrm{g} / \mathrm{ml}\right)$, respectively compared to vincristine sulfate $\left(\mathrm{LC}_{50}: 0.45\right.$ $\mu \mathrm{g} / \mathrm{ml})$. The $\mathrm{n}$-hexane extract showed no antimicrobial activity against the tested micro-organisms but the methanol extract showed a strong zone of inhibition $(25 \mathrm{~mm})$ against Staphylococcus aureus and a moderate zone of inhibition $(10 \mathrm{~mm})$ against Shigella boydii. Both the extracts exhibited almost zero haemolysis.
\end{abstract}

Keywords: Aphanamixis polystachya; Biological activity; Antioxidants; Cytotoxicity; Antimicrobial activity; Haemolysis

\section{Introduction}

Currently, more than half of drugs in clinical uses and about $50 \%$ of the world's 25 bestselling pharmaceutical agents are from natural-product origin. As a source of chemical substances with potent therapeutic effects, medicinal plants have been used in all cultures, since time immemorial. Traditionally used medicinal plants have recently attracted the attention of the pharmaceutical and scientific communities. This has involved the isolation and identification of secondary metabolites produced by plants and their use as active principles in medicinal chemical preparations (Taylor et al., 2001). Many of the plant secondary metabolites are constitutive, existing in healthy plants in their biologically active forms, but others occur as inactive precursors and are activated in response to tissue damage or pathogen attack (Osbourne, 1996). The array of secondary metabolites produced by plants is daunting, with wide ranging chemical, physical and biological activities. These constitute a source of bioactive substances and presently scientific interest has increased due to the search for new drugs of plant origin.

A. polystachya has been reported to possess analgesic, antimicrobial, antioxidant, antitumor, cytotoxic, laxative, insecticidal, membrane stabilizing and thrombolytic 
(Bamwal, 2005; Nabi et al. 2009; Hossain et al. 2009) activities. Extracts of $A$. polystachya seeds contain highly concentrated nutraceutical and biologically active antioxidant compounds and have applications in medicinal, pharmaceutical, food and cosmetic industries(Azam et al. 2005; Sikder et al., 2010; Chowdhury and Rashid, 2003; Talukder and Howse, 1993). Taste of A. polystachya seed is extremely bitter. After removal of its oil, the fruits are generally used as fertilizer (Chatterjee and Kundu, 1967). The pharmacologically active phytochemicals of Aphanamixis species have been widely studied over the decades. Among all, most studied Aphanamixis species are $A$. grandifolia and A. polystachya. Triterpenoids, sesquiterpenoids, diterpenoids, alkaloids, sterols, flavonoids and lignins are the common compounds isolated from Aphanamixis species. These constituents of Aphanamixis and their extracts exhibit various bioactivities, mostly cytotoxic, antitumour, antimicrobial and antimalarial activities. However, their relative toxicities are not known; only few reports of target organ toxicities or even side effects exist in the literature. In addition, many limonoids with novel carbon skeletons and pronounced bioactivities are found in Aphanamixis plants, appealing substantial attention to Aphanamixis from both natural product chemists and biologists.

Along with leaves, barks and stem bark, seeds extracts are reported as a rich source of phytochemicals and among the extracts n-hexane extract showed highest antimicrobial activity against Shigella dysenteriae and Candida albicans, whereas at the same concentration of methanol extract showed highest zone of inhibition against Staphylococcus aureus (Apu et al., 2013).

Objectives of this study were evaluation of A.phanamixis polystachya seed extracts for phenolic contents and determination of various in vitro biological activities such as free radical scavenging, thrombolytic activity, membrane stabilizing, antimicrobial, haemolytic activity and brine shrimp lethality bioassay for preliminary clinical evaluation of the extract. This seed extracts can be potential for drug development and hence Bangladesh would achieve economic benefits utilizing this possible source.

\section{Materials and methods}

\section{Materials and chemicals}

Nutrient agar and nutrient broth were purchased from HiMedia Laboratories Pvt. Ltd., Mumbai, India. Folin-Ciocalteu reagent, DPPH (2,2-diphenyl-1 -picrylhydrazyl), dimethyl sulfoxide, n-hexane and methanol were obtained from Sigma-Aldrich Chemie GmbH, Germany.

\section{Extraction procedure}

Oil content of $A$. polystachya seed was determined by soxhlet extraction using $n$-hexane as solvent (Baümler $e t$ al. 2015; Bhutada et al., 2016). About 100g dried seed powder was taken in a porous bag. The bag was placed inside a soxhlet apparatus that was suspended above a 500 $\mathrm{ml}$ round-bottom flask containing about $300 \mathrm{ml}$ of $n$-hexane and methanol below a reflux condenser. The flask was heated using $500 \mathrm{ml}$ mantle (Glassco Laboratory Instruments, India). The extract was concentrated using rotary evaporator and further dried using fan before utilized for further tests. Table I shows the weight of extracts using $\mathrm{n}$-hexane and methanol as solvent.

\section{Total phenolic content determination}

The total phenolic content was measured according to Folin-Ciocalteu method (Rabeya et al., 2020). $0.5 \mathrm{ml}(2$ $\mathrm{mg} / \mathrm{ml}$ ) of each extract was added with $2.5 \mathrm{ml}$ of Folin-Ciocalteu reagent (10 times diluted with water) and 2 $\mathrm{ml} 7.5 \%(\mathrm{w} / \mathrm{v}) \mathrm{Na}_{2} \mathrm{CO}_{3}$. The mixture was incubated for 20 min at room temperature then absorbance was measured at $760 \mathrm{~nm}$ using UV-1700 PharmaSec UV-Visible Spectrophotometer, Shimadzu. Phenolic content of the samples was determined as GAE/g of extract using standard curve prepared 0 to $100 \mu \mathrm{g} / \mathrm{ml}$ gallic acid solutions.

\section{Determination of DPPE free radical scavenging activity}

The free-radical scavenging activity of A. polystachya seed extracts were measured by the decrease in absorbance of the methanol solution of DPPH (2,2-diphenyl-1-picrylhydrazyl) by the method developed by Williams et al. (1995). A stock solution of $20 \mu \mathrm{g} / \mathrm{ml}$ of DPPH in $99.8 \%$ methanol was prepared by dissolving $2 \mathrm{mg}$ of DPPH in $100 \mathrm{ml}$ methanol. A stock solution of $1000 \mu \mathrm{g} / \mathrm{ml}$ of A.polystachya extract was prepared by dissolving $2 \mathrm{mg}$ of each extract in $2 \mathrm{ml}$ of methanol and from there solutions of varying concentrations such as $500,250,125,62.3,31.25,15.625,7.812,3.906$, 1.953 and $0.976 \mu \mathrm{g} / \mathrm{ml}$ were prepared by serial dilution technique. $3 \mathrm{ml}$ of the prepared DPPH solution in methanol was added to $2 \mathrm{ml}$ of the A. polystachya extracts of varying concentrations. The solutions were kept in the dark for 30 min and the absorbance of the sample as well as the blank was measured at $517 \mathrm{~nm}$ usingUV-Vis Spectrophotometer.

The scavenging activity was expressed as Inhibition (\%) as given in the equation below:

Inhibition $(\%)=\left(\mathrm{A}_{\text {blank }}-\mathrm{A}_{\text {sample }}\right) / \mathrm{A}_{\text {blank }} \mathrm{X} 100$ 
Table I. Weight of extracts using n-hexane and methanol as solvent

\begin{tabular}{lll}
\hline Wt. of seed powder $(\mathrm{g})$ & Solvent used & Wt. of extract $(\mathrm{g})$ \\
\hline 102.85 & n-hexane & 37.37 \\
100.12 & Methanol & 29.03 \\
\hline
\end{tabular}

Table II. Total phenolic content of different extracts by UV-Vis absorbance

\begin{tabular}{lll}
\hline Solvent & Absorbance at $760 \mathrm{~nm}$ & $\begin{array}{l}\text { Total phenolic content (mg } \\
\text { GAE/g of extract) }\end{array}$ \\
\hline n-hexane & 0.405 & 12.0 \\
Methanol & 0.396 & 11.7 \\
Blank & 0.116 & 2.95 \\
\hline
\end{tabular}

Table III. In vitro thrombolytic activity of the prepared extracts

\begin{tabular}{llll}
\hline Sample name & Wt. of clot $(\mathrm{mg})$ & $\begin{array}{l}\text { Wt. of clot after } \\
\text { disruption }(\mathrm{mg})\end{array}$ & \% Clot lysis \\
\hline n-hexane extract & 693.0 & 562.4 & 18.85 \\
Methanol extract & 541.8 & 414.5 & 23.49 \\
Distilled water & 1158.0 & 1049.7 & 9.35 \\
Streptokinase & 557.0 & 201.0 & 65.16 \\
\hline
\end{tabular}

Table IV. Effect of different extracts of $A$. polystachya on inhibiting hypotonic solution induced haemolysis of erythrocyte membrane

\begin{tabular}{lcc}
\hline Sample & $\begin{array}{c}\text { Optical density } \\
\text { at } 540 \mathrm{~nm}\end{array}$ & $\begin{array}{c}\text { \% inhibition of hypotonic } \\
\text { medium induced haemolysis }\end{array}$ \\
\hline n-hexane extract in hypotonic solution & 1.489 & 18.2 \\
Methanol extract in hypotonic solution & 1.234 & 32.2 \\
Acetyl salicylic acid in hypotonic solution & 1.053 & 42.1 \\
Hypotonic-buffered saline solution (control) & 1.820 & - \\
\hline
\end{tabular}


where, $\mathrm{A}_{\text {blank }}$ is the absorbance of the blank sample and $\mathrm{A}_{\text {sample }}$ is the absorbance of the test sample. Inhibition (\%) was plotted against the respective extract concentrations and $\mathrm{IC}_{50}$ values were determined using extrapolation. BHT (tert-butyl-1- hydroxy toluene) was used as positive control.

\section{In vitro thrombolytic activity}

The thrombolytic activity of all extracts was evaluated by a method using streptokinase as standard substance. Commercially available lyophilized Altepase (Streptokinase) vial (Beacon pharmaceutical Ltd) of 15,00,000 I.U., was collected and $5 \mathrm{ml}$ sterile distilled water was added and mixed properly. This suspension was used as a stock from which $100 \mu \mathrm{l}$ (30,000 I.U) was used for in vitro thrombolysis. Aliquots $(4 \mathrm{ml})$ of venous blood were drawn from healthy volunteers, which were distributed in four different pre-weighed sterile vials and incubated at $37^{\circ} \mathrm{C}$ for $45 \mathrm{~min}$. After clot formation, the serum was completely removed without disturbing the clot and each tube having clot was again weighed to determine the clot weight (clot weight $=$ weight of clot containing tube - weight of tube alone). Each vial containing pre-weighed clot, $100 \mu \mathrm{l}$ aqueous solutions of the crude extracts $(10 \mathrm{mg} / \mathrm{ml})$ were added separately. As a positive control, $100 \mu \mathrm{l}$ of streptokinase and as a negative non thrombolytic control, $100 \mu \mathrm{l}$ of distilled water were separately added to the control vials. All the vials were then incubated at $37^{\circ} \mathrm{C}$ for $90 \mathrm{~min}$ and observed for clot lysis. After incubation, the released fluid was removed and tubes were again weighed to observe the difference in weight after clot disruption. Difference obtained in weight taken before and after clot lysis was expressed as percentage of clot lysis as shown below:

$\%$ of clot lysis $=($ wt. of released clot/clot wt. $) \times 100$

\section{Determination of membrane stabilizing activity}

Human RBCs were collected from the healthy male, free from diseases and blood group $\mathrm{A}^{+}$(A positive). The collected RBCs were kept in a test tube with an anti-coagulant EDTA under standard conditions at temperature $23 \pm 2^{\circ} \mathrm{C}$ and relative humidity $55 \pm 10 \%$. The blood was washed with $10 \mathrm{ml}$ isotonic solution $(154 \mathrm{mM} \mathrm{NaCl})$ in $10 \mathrm{mM}$ sodium phosphate buffer ( $\mathrm{pH}$ 7.4) through centrifuge action for 10 min at $3000 \mathrm{rpm}$. The suspension finally collected was the stock erythrocyte (RBC) suspension.

\section{Hypotonic solution- induced haemolysis}

The experiment was carried out with hypotonic solution. The test sample consisted of stock erythrocyte (RBC) suspension $(30 \mu \mathrm{l})$ with $4.5 \mathrm{ml}$ of hypotonic solution $(50 \mathrm{mM} \mathrm{NaC1})$ in
$10 \mathrm{mM}$ sodium phosphate buffer saline (pH 7.4) and $0.5 \mathrm{ml}$ of the different extract $(2.0 \mathrm{mg} / \mathrm{ml})$ or acetyl salicylic acid $(0.10 \mathrm{mg} / \mathrm{ml})$. The acetyl salicylic acid was used as a reference standard. The mixtures were incubated for $10 \mathrm{~min}$ at room temperature, centrifuged for $10 \mathrm{~min}$ at $3000 \mathrm{rpm}$ and the absorbance (OD) of the supernatant was measured at 540 $\mathrm{nm}$ using UV-Vis spectrophotometer. The percentage inhibition of either haemolysis or membrane stabilization was calculated using the following equation:

$\%$ inhibition of haemolysis $=100 \times\left\{\left(\mathrm{OD}_{1}-\mathrm{OD}_{2} / \mathrm{OD}_{1}\right\}\right.$

where, $\mathrm{OD}_{1}$ is optical density of hypotonic-buffered saline solution alone (control) and $\mathrm{OD}_{2}$ is optical density of test sample in hypotonic solution.

\section{Heat-induced haemolysis}

Aliquots $(5 \mathrm{ml})$ of the isotonic buffer containing $10 \mathrm{mg} / \mathrm{ml}$ of different extracts were put into two duplicate sets of centrifuge tubes. The vehicle, in the same amount, was added to another tube as control. Erythrocyte suspension $(30 \mu \mathrm{l})$ was added to each tube and mixed gently by inversion. One pair of the tubes was incubated at $54^{\circ} \mathrm{C}$ for $20 \mathrm{~min}$ in a water bath. The other pair was maintained at $0-5^{\circ} \mathrm{C}$ in an ice bath. The reaction mixture was centrifuged for $3 \mathrm{~min}$ at $1300 \mathrm{rpm}$ and the absorbance of the supernatant was measured at 540 $\mathrm{nm}$. The percentage inhibition or acceleration of haemolysis was calculated according to the equation:

$\%$ inhibition of haemolysis $=100 \times\{1-$ $\left.\left(\mathrm{OD}_{2}-\mathrm{OD}_{1}\right) /\left(\mathrm{OD}_{3}-\mathrm{OD}_{1}\right)\right\}$

where, $\mathrm{OD}_{1}$ is test sample unheated, $\mathrm{OD}_{2}$ is test sample heated and $\mathrm{OD}_{3}$ is control sample heated

\section{Brine shrimp lethality bioassay}

Brine shrimp lethality bioassay technique of Meyer et al. (1982) was applied for the determination of cytotoxic property of the prepared extracts. 38 gm sea salt (pure $\mathrm{NaC} 1$ ) was weighed, dissolved in 11 distilled water and filtered off to get a clear solution. Brine shrimp eggs were added to one side of the tank containing sea water and that side was covered and oxygen was supplied constantly. The shrimp was allowed to hatch for $24 \mathrm{~h}$ and to be matured as nauplii. After that 10 living brine shrimps were transferred to each test tube containing $5 \mathrm{ml}$ of saline water. Stock solution was prepared by dissolving $4 \mathrm{mg}$ of each extract in $200 \mu \mathrm{l}$ of DMSO and then solutions of varying concentrations such as $400,200,100,50,25,12.5,6.25,3.125,1.563$ and 0.781 $\mu \mathrm{g} / \mathrm{ml}$ was prepared by serial dilution technique. DMSO was used as negative control and vincristine sulphate as positive 
control. Measured amount of the vincristine sulphate was dissolved in DMSO to get an initial concentration of 20 $\mu \mathrm{g} / \mathrm{ml}$ from which serial dilutions are made using DMSO to get $10,5,2.5,1.25,0.625,0.312,0.156,0.0781$ and 0.0390 $\mu \mathrm{g} / \mathrm{ml}$. Then the solutions were added to the premarked test tubes containing 10 live brine shrimp nauplii in $5 \mathrm{ml}$ simulated saline water and $100 \mu \mathrm{l}$ of DMSO. After $24 \mathrm{~h}$, the test tubes were inspected using a magnifying glass in colony counter in presence of light. The number of the survived nauplii in each vial was counted. From the data, the percentage of lethality of the brine shrimp was calculated for each concentration. The median lethal concentration $\left(\mathrm{LC}_{50}\right)$ of the test samples was obtained by a plot of percentage of shrimp killed against the logarithm of the sample concentration.

Percentage of brine shrimp killed in a particular extract $=$ brine shrimp killed in extract/total brine shrimp taken $\mathrm{x} 100$

\section{Antimicrobial screening}

The Kirby-Bauer disc diffusion method (Bauer et al., 1966) was used to evaluate the antimicrobial potential of the prepared extracts against $5 \mathrm{~g}$ positive bacteria (Bacillus cereus, Bacillus rnegaterium, Bacillus subtilis, Sarcina lutea and Staphylococcus aureus), $8 \mathrm{~g}$ negative bacteria (Escherichia coli, Salmonella paraiyphi, Salmonella typhi, Shigella boydii, Pseudomonas aeruginosa, Vibrio mimicus and Vibrio parahemolyticus) and 3fungi (Aspergillus niger, Candida albicans and Sacharomyces cerevacae) which were collected as pure cultures from the Institute of Nutrition and Food Science (INFS), University of Dhaka. $8.6 \mathrm{~g}$ of nutrient agar medium powder was taken in a conical flask and $300 \mathrm{ml}$ of distilled water was added to it to prepare the required volume of the medium. The contents were heated in a water bath to make a clear solution. The $\mathrm{pH}\left(\right.$ at $\left.25^{\circ} \mathrm{C}\right)$ was adjusted to 7.2-7.6 using $\mathrm{NaOH}$. $10 \mathrm{ml}$ and $5 \mathrm{~m} 1$ of the prepared medium were then transferred in screw cap test tubes to prepare plates and slants respectively. The test tubes were then capped and sterilized by autoclaving with REXMED RAU-323 autoclave at $15 \mathrm{Ibs} /$ inch $^{2}$ pressure at $121^{\circ} \mathrm{C}$ for 20 minutes. The slants were used for making fresh culture of bacteria and fungi which were in turn used for sensitivity study.

The test organisms were transferred from the subculture to the test tubes containing about $10 \mathrm{ml}$ of melted and sterilized agar medium with the help of a sterilized transfer loop in Safe FAST Top Microbiological Safety Cabinet (aseptic area). The test tubes were shaken by rotation to get a uniform suspension of the organisms and the turbidity was compared to the $0.5 \mathrm{McF}$ arland standards (Zapata and Ramirez-Arcos, 2015) which confirmed the growth. The bacterial and fungal suspension was immediately transferred to sterilized petri dishes. The petri dishes were rotated several times clockwise and anticlockwise to assure homogenous distribution of the test organisms in the media.

$30 \mathrm{mg}$ of each of the methanol and n-hexane extracts were dissolved in $750 \mu \mathrm{l}$ of methanol in order to obtain the desired concentration of each extract in an aseptic condition. $10 \mu \mathrm{l}$ of the solution was applied to sterile filter paper discs of $6 \mathrm{~mm}$ diameter using a micropipette so that each disc had a concentration of $400 \mu \mathrm{g} /$ disc under the laminar hood and the discs were dried.The sample discs and the standard ciprofloxacin disc were placed gently on the previously marked zones in the agar plates pre-inoculated with test bacteria and fungi. The plates were kept in a refrigerator at 4 ${ }^{\circ} \mathrm{C}$ for about $24 \mathrm{~h}$ upside down to allow sufficient diffusion of the materials form the discs to the surrounding agar medium. The plates were then inverted and kept in an MMM FRIOCELL Cooled Incubator with Forced Air Convection at $37{ }^{\circ} \mathrm{C}$ for 24 hours. After incubation, the antimicrobial activities of the test materials were determined by measuring the diameter of the zones of inhibition in millimeters with a transparent scale.

\section{Haemolysis test}

Seed extracts of concentration $1 \mathrm{mg} / \mathrm{ml}$ were prepared in $10 \%$ DMSO. Human $\mathrm{A}^{+}$whole blood was used and the cells were pelleted by centrifugation using High Speed Refrigerated Centrifuge H-9R KOKUSAN CORPORATION, JAPAN, at $6000 \mathrm{rpm}$ for $10 \mathrm{~min}$ and the supernatant was discarded. The final pellet was diluted $1: 9(\mathrm{v} / \mathrm{v})$ in sterile $0.9 \% \mathrm{NaCl}$ saline solution and again centrifuged at $6000 \mathrm{rpm}$ for $10 \mathrm{~min}$. Red cell suspensions ( $1 \mathrm{ml}$ of final volume) were incubated with Tryptone Soya Agar medium at $37^{\circ} \mathrm{C}$ for $24 \mathrm{~h}$. After that using a sterile $8 \mathrm{~mm}$ cork borer, two holes were made on the blood agar medium. Using a micropipette $100 \mu \mathrm{l}$ of each crude extract was applied on the holes made in the medium. Total lysis of erythrocyte suspension was obtained by incubating the cells at $37^{\circ} \mathrm{C}$ after $24 \mathrm{~h}$. Hemolytic levels were observed by rupture of red blood cells with sample solution. Red blood cell hemolysis was also studied by Olympus Culture Microscope, CKX41.

\section{Results and discussions}

\section{Total phenolic content}

The phenolic compounds exert their antioxidant properties by redox reaction, which can play an important role in absorbing and neutralizing free radicals, quenching singlet and triplet oxygen or decomposing peroxides. The antioxidative effect is mainly due to phenolic components 
such as flavonoids, phenolic acids and phenolic diterpenes. In the alkaline conditions phenols ionizes completely. The absorbance value reflects the total phenolic content in the compound.

$$
\begin{aligned}
& \text { Phenols }+\mathrm{Na}_{2} \mathrm{CO}_{3} \longrightarrow \text { Ionized phenols } \\
& \text { Ionized phenols }+ \text { Folin-Chiocalteu reagent } \longrightarrow
\end{aligned}
$$

(Yellow)

Folin-Chiocalteu reagent complex

The n-hexane and methanolic extracts of the seeds of A.phanamixis polystachya having concentration of $2 \mathrm{mg} / \mathrm{ml}$ were tested for the total phenolic content using Folin-Ciocalteu reagent and expressed as $\mathrm{mg}$ of $\mathrm{GAE} / \mathrm{g}$ of extractives (Table II).

Among the extractives of A.phanamixis polystachya seed, the highest phenolic content $12.0 \mathrm{mg} \mathrm{GAE} / \mathrm{g}$ was found in the n-hexane extract followed by methanol extract $(11.7 \mathrm{mg}$ GAE/g). The high phenolic contents of the extracts were present may be due the presence of flavonoids, phenolic acids, anthocyanins and non-flavonoid phenolic compounds (Cosmulescu et al., 2017).

Free radical scavenging activity of $n$-hexane extract, methanol extract and BHT

Free radicals and some reactive nitrogen species trigger and increase cell death mechanisms within the body such as apoptosis and in extreme cases necrosis and result in diseases such as cancer, thrombosis, arthritis, diabetes etc. The antioxidant potential of the n-hexane and methanol extracts of $A$. polystachya was assayed from the bleaching of purple colored methanol solution of DPPH radical by the plant extract as compared to that of BHT by UV-Vis spectrophotometer.

DPPH is a stable free radical with an unpaired electron that is delocalized over the entire molecule and possesses a purple colour with a maximum absorption at $517 \mathrm{~nm}$ in methanol; hence scavenging the DPPH radical caused a decrease in absorption readings over time. The extent of decrease in DPPH absorption is directly proportional to the concentration of the radicals that are being scavenged. DPPH assay is based on both electron transfer (SET) and hydrogen atom transfer (HAT) reactions. DPPH is a lipophilic radical with limited accessibility to the hydrophilic components present in the sample thereby requiring methanol in the reaction mixture to increase solubility. The antioxidant properties of different extracts were measured in terms of free radical scavenging activity.

In this investigation, the methanol extract showed a very strong free radical scavenging activity with an $\mathrm{IC}_{50}$ value $22.34 \mu \mathrm{g} / \mathrm{ml}$ and the $\mathrm{n}$-hexane extract showed moderate free radical scavenging activity with $\mathrm{IC}_{50}$ value $63.05 \mu \mathrm{g} / \mathrm{ml}$ compared to BHT, which showed an $\mathrm{IC}_{50}$ value of 14.01 $\mu \mathrm{g} / \mathrm{ml}$ (Fig. 1A, 1B, 1C and 1D). The significant free radical activity of the methanol extract may be due to the presence of polyphenolic compounds such as flavonoids and tannins and this in turn may be attributable to the hydrogen or electron donating ability of the groups present in the structure and the methanol extract can be further investigated for the treatment of free-radical mediated diseases (Saeed et al., 2012).

\section{In vitro thrombolytic activity}

Thrombolysis is the breakdown (lysis) of blood clots by pharmacological means. Most thrombolytic agents work by activating the enzyme plasminogen, which clears the cross-linked fibrin mesh (the backbone of a clot). This makes the clot soluble and subject to further proteolysis by other enzymes, and restores blood flow over occluded blood vessels. Thus, thrombolytic agents are useful for the treatment of myocardial infarction, thromboembolic strokes, deep vein thrombosis to clear a blocked artery and avoid permanent damage to the perfused tissue (eg. myocardium, brain, leg).

For the discovery of cardio protective drugs from natural sources, the n-hexane and methanol extracts of A.phanamixis polystachya seed of concentration of $10 \mathrm{mg} / \mathrm{ml}$ were assessed for thrombolytic activity. Streptokinase was used as the positive control and distilled water as the negative control. The results are presented in Table III. Addition of $100 \mu \mathrm{l}$ Streptokinase, a positive control (30,000 IU) to the clots and subsequent incubation for $90 \mathrm{~min}$ at $37^{\circ} \mathrm{C}$, showed $65.16 \%$ lysis of clot. On the other hand, distilled water was treated as negative control which exhibited negligible percentages of lysis of clot $(9.35 \%)$. The mean difference in clot lysis percentages between positive and negative control was found statistically significant. In this study, methanol extract of $A$. polystachya exhibited significant thrombolytic activity $(23.49 \%)$ and n-hexane extract exhibited moderate thrombolytic activity $(18.84 \%)$ compared to the negative control. The thrombolytic activity of the extracts may be due to the presence of alkaloids, flavonoids, tannins and terpenoids in large quantities which are said to exert clot lysis activity (Bhowmick et al., 2014). The compounds that are present in the extracts can be isolated and used as potent thrombolytic agent against thrombosis disorder. 


\section{Membrane stabilizing activity}

The vitality of cells depends on the integrity of their membranes. Exposure of red blood cell to injurious substances such as hypotonic medium and phenyl hydrazine results in lysis of its membrane accompanied by haemolysis and oxidation of haemoglobin. The haemolytic effect of hypotonic solution is related to excessive accumulation of fluid within the cell resulting in the rupturing of its membrane. The effect of synthetic and herbal anti-inflammatory agents on the stabilization of erythrocyte membrane exposed to heat induced and hypotonic solution has been studied extensively. The erythrocyte membrane resembles the lysosomal membrane and as such, the effect of drugs on the stabilization of erythrocyte could be extrapolated to the stabilization of lysosomal membrane.

The results of the inhibition of the hypnotic solution induced haemolysis by the $\mathrm{n}$-hexane and methanol extract of $A$. polystachya of concentration of $2 \mathrm{mg} / \mathrm{ml}$ and acetyl salicylic acid of concentration $0.1 \mathrm{mg} / \mathrm{ml}$ are shown in the Table IV. Table V shows the effect of different extractives

\begin{tabular}{|c|c|c|}
\hline Sample & $\begin{array}{l}\text { Optical density } \\
\text { at } 540 \mathrm{~nm}\end{array}$ & $\begin{array}{l}\% \text { inhibition of heat } \\
\text { induced haemolysis }\end{array}$ \\
\hline $\mathrm{n}$-Hexane extract in isotonic solution before heating & 1.467 & - \\
\hline Methanol extract in isotonic solution after heating & 1.452 & 70.17 \\
\hline Methanol extract in isotonic solution before heating & 1.233 & - \\
\hline Acetyl salicylic acid in isotonic solution after heating & 1.389 & 71.90 \\
\hline Acetyl salicylic acid in isotonic solution after heating & 1.164 & - \\
\hline Isotonic - buffered saline solution after heating (control) & 1.965 & - \\
\hline
\end{tabular}

of A. polystachya on inhibiting heat induced haemolysis of erythrocyte membrane. Sample Optical density at $540 \mathrm{~nm}$ $\mathrm{n}$-Hexane extract in isotonic solution heated 1.954 n-Hexane extract in isotonic solution unheated 1.467 methanol extract in isotonic solution heated 1.452 methanol extract in isotonic solution unheated 1.233 acetyl salicylic acid in isotonic solution heated 1.389 acetyl salicylic acid in isotonic solution unheated 1.164 Isotonic -buffered saline solution heated (control) 1.965 .

The results showed that the methanol extract was potent on human erythrocyte adequately protecting it against both hypotonic solution (32.2\%) and heat induced lyses (70.17\%). The activity was comparable to that of a standard anti-inflammatory drug (Acetyl Salicylic Acid) which had an activity of $42.1 \%$ against hypnotic solution lyses and $71.9 \%$ against heat induced lyses. The n-hexane extract showed moderate membrane stabilizing activity against hypnotic solution (18.2\%) induced lyses but no significant activity against heat induced lyses $(2.21 \%)$. The significant membrane stabilizing ability of methanol extract may be due toflavonoids which exert profound stabilizing effects on

\section{Table V. Effect of different extracts of $A$. polystachya on inhibiting heat induced haemolysis of erythrocyte membrane}


Table VI. Antimicrobial screening of different extracts of A.phanamixis polystachya

\begin{tabular}{llccc}
\hline $\begin{array}{l}\text { Test organism } \\
\text { used }\end{array}$ & Organism name & $\begin{array}{c}\text { Ciprofloxacin } \\
(5 \mu \mathrm{g} / \mathrm{disc})\end{array}$ & $\begin{array}{c}\mathrm{n} \text {-hexane extract } \\
(400 \mu \mathrm{g} / \mathrm{disc})\end{array}$ & $\begin{array}{c}\text { Methanol extract } \\
(400 \mu \mathrm{g} / \mathrm{disc})\end{array}$ \\
\hline Gram positive & Bacillus cereus & 40 & - & - \\
bacteria & Bacillus megaterium & 41 & - & - \\
& Bacillus subtilis & 45 & - & - \\
& Staphylococcus aureus & 43 & - & - \\
& Sarcina lutea & 40 & - & - \\
\hline Gram negative & Salmonella paraiyphi & 45 & - & - \\
bacteria & Salmonella typhi & 40 & - & - \\
& Vibrio parahemolyticus & 41 & - & - \\
& Escherchia coli & 41 & - & - \\
& Vibrio mimicus & 45 & - & 10 \\
& Shigella dysenteriae & 42 & - & - \\
\hline Fungi & Pseudomonas aeruginosa & 39 & - & - \\
& Shigella boydii & 42 & - & - \\
& Saccharomyces cerevaceae & 42 & - & \\
& Candida albicans & 45 & & - \\
& Aspergillus niger & 40 & &
\end{tabular}

lysosomes. In vitro and in vivo experimental animal or tannin and saponins which have the ability to bind cations and other biomolecules are able to stabilize erythrocyte membrane (Schaffer et al., 1989).

\section{Brine shrimp lethality bioassay}

The n-hexane and methanol extracts of the seeds of $A$. polystachya were tested for brine shrimp lethality bioassay following the procedure of Meyer et al. (1982). The lethal concentration, $\mathrm{LC}_{50}$ of the test samples after $24 \mathrm{~h}$ was obtained by a plot of percentage of the shrimps died against the logarithm of the sample concentration (toxicant concentration) and the best-fit line was obtained from the curve data by means of regression analysis (Fig. 2A, 2B, 2C). Vincristine sulfate (VS) was used as positive control and the $\mathrm{LC}_{50}$ was found to be $0.45 \mu \mathrm{g} / \mathrm{ml}$. The $\mathrm{LC}_{50}$ values of n-hexane and methanol extracts were found to be 13.45 $\mu \mathrm{g} / \mathrm{ml}$ and $1.61 \mu \mathrm{g} / \mathrm{ml}$ respectively (Fig. 2D). The methanol extract showed significant lethality whereas the n-hexane extract showed moderate activity compared to the positive control. The cytotoxicity exhibited by the extracts may be due to the presence of alkaloids, flavonoids and terpenoids in them (Sivasankar et al. 2013). The cytotoxicity exhibited by the extracts indicated that further bioactivity guided investigation can be done to find out potent antitumor and pesticidal compounds from this plant.

\section{Antimicrobial screening}

The diameter zones of inhibition of the extracts $(400 \mu \mathrm{g} / \mathrm{disc})$ were measured in millimeters to determine the results of antimicrobial activity and compared with ciprofloxacin $(5 \mu \mathrm{g} / \mathrm{disc})$. Table VI shows the antimicrobial screening of different extracts of A.phanamixis polystachya. All the microorganisms were resistant to the n-hexane extract but the methanol extract showed strong antimicrobial activity of 25 $\mathrm{mm}$ against the Gram-positive bacteria Staphylococcus aureus which although less than that of Ciprofloxacin (45 $\mathrm{mm})$ was significant. It also showed mild antimicrobial activity of $10 \mathrm{~mm}$ against Shigella boydii. This showed that the polar solvent extract had higher antimicrobial activity than the non-polar solvent extract and this may be due to the presence of alkaloids, flavonoids, saponins and terpenoids in 
the methanol extract (Balouiri et al., 2016). Interestingly, the test samples did not show any activity against the three fungi used in the experiment; these extracts may have activities with other fungi strains. These results suggesting that the inhibitory property may also be strains-specific (or even substrains-specific). These types of results also supported by other studies (Synytsya et al., 2017; Sitarek et al., 2020).
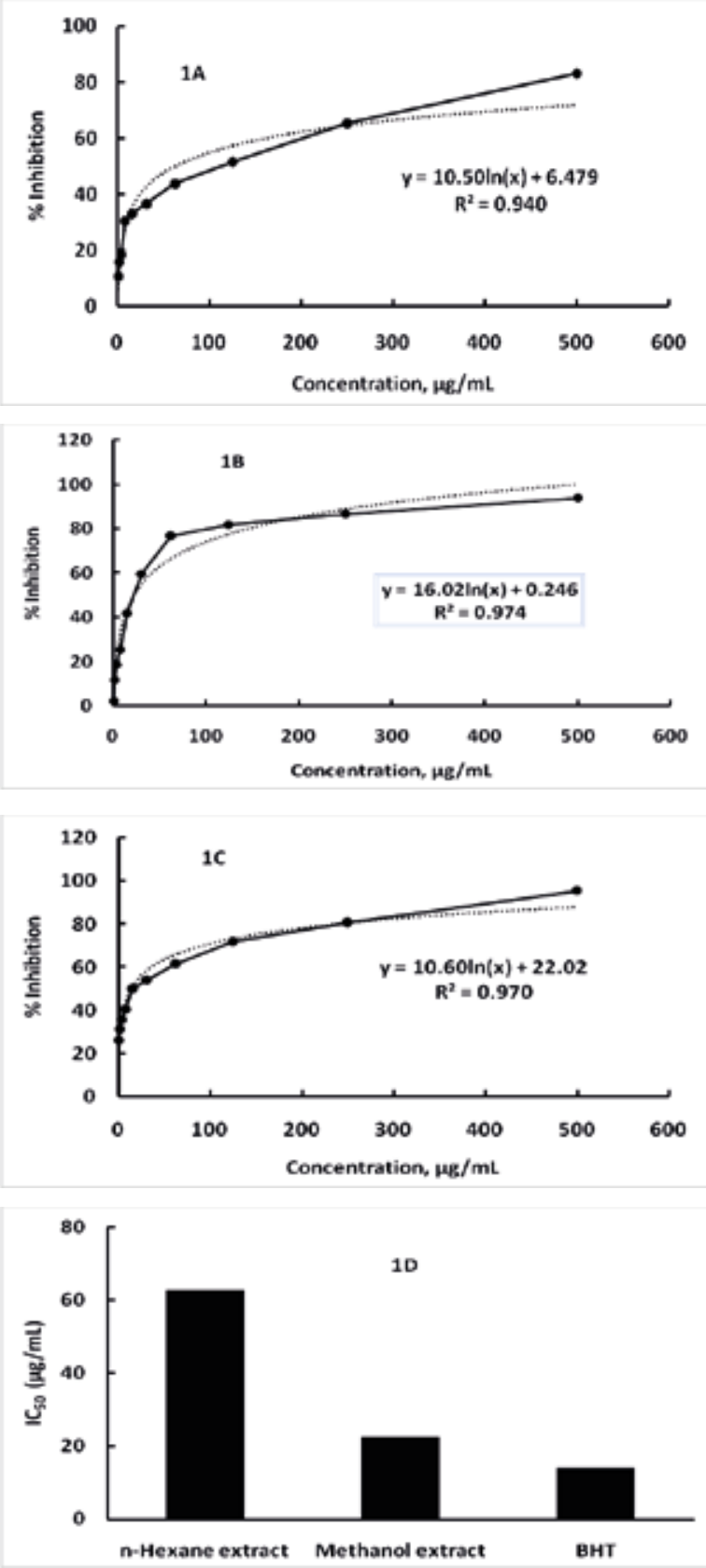

Fig. 1. Free radical scavenging activity of n-Hexane extract (A), methanol extract (B), BHT (C) and $\mathrm{IC}_{50}$ values of the test samples of plant of A.phanambcis polystachya (D)
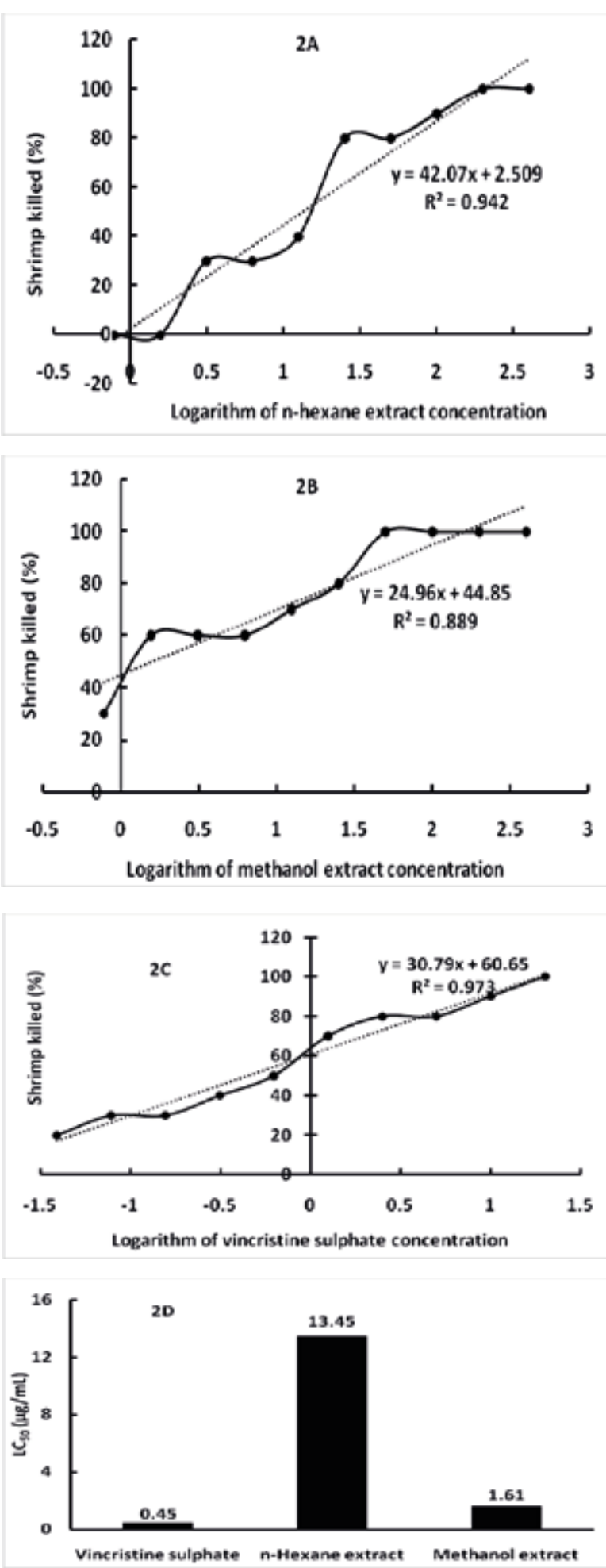

Fig. 2. Effect of $n$-hexane extract (2A), methanol extract (2B), vincristine sulphate (2C) on brine shrimp nauplii and $\mathrm{LC}_{50}$ values (2D) of the different extractives of $A$.phanamixis polystachya 

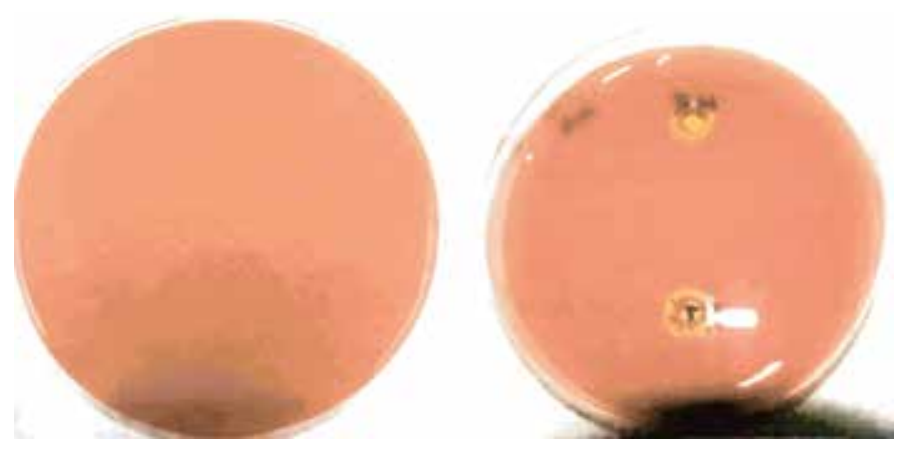

Fig. 3. Blood agar medium in normal saline (reference) (left) and blood agar medium with the extracts after incubation

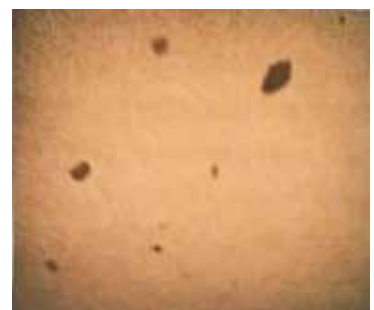

4A

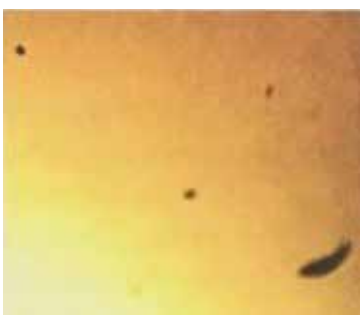

$4 B$

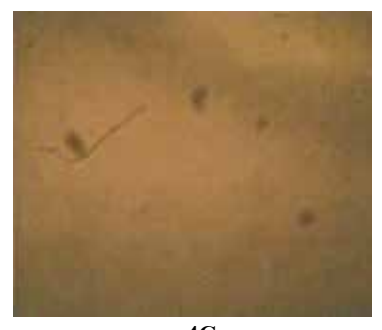

$4 \mathrm{C}$

Fig. 4. Red blood cells in (A) normal saline (B) n-hexane extract (C) methanol extract after $24 \mathrm{~h}$ incubation for

\section{Haemolysis activity}

The haemolytic activity of the n-hexane and methanol extracts was carried out on blood agar medium to determine their cytotoxicity towards red blood cells. Table VII shows the zone of destabilization of the enthrocyte membrane due to the application of the seed extracts.

After $24 \mathrm{~h}$ incubation period, a very small zone of destabilization was observed in case of n-hexane extract $(2$ $\mathrm{mm}$ ) and methanol extract ( $4 \mathrm{~mm}$ ). Fig. 3 shows the zone of destabilization we can say that almost $0 \%$ haemolysis was observed for the two extracts at a concentration of $1 \mathrm{mg} / \mathrm{ml}$. For further clarification, the blood agar plate was viewed under the optical microscope (Fig. 4A, 4B, 4C) to see whether cell death has taken place or not. The samples tested did not show any rupture or agglomeration and therefore the cell membranes did not break down and the hemoglobin did not come out from the red blood cells. Therefore, the extracts were highly hemo-compatible and are safe for clinical applications and further in vivo and phytochemical tests must be carried out in order to establish these extracts as a medicinal agent.

Table VII. Zone of destabilization of the enthrocyte membrane due to the application of the seed extracts

\begin{tabular}{lccc}
\hline Sample name & $\begin{array}{l}\text { Extract zone before } \\
\text { incubation }(\mathrm{mm})\end{array}$ & $\begin{array}{l}\text { Extract zone after } \\
\text { incubation }(\mathrm{mm})\end{array}$ & $\begin{array}{l}\text { Enthrocyte destabilization } \\
\text { zone due to extract }(\mathrm{mm})\end{array}$ \\
\hline n-hexane extract & 8 & 10 & 2 \\
Methanol extract & 8 & 12 & 4 \\
\hline
\end{tabular}




\section{Conclusions}

Aphanamixis polystachya seed extract is a potential source of different medicinal compounds. The n-hexane and methanol extract showed significant phenolic content of 12.0 and 11.7 $\mathrm{mg}$ GAE/g, respectively. The methanol extract of the seeds showed significant in vitro antioxidant, thrombolytic, membrane stabilizing, cytotoxic and antimicrobial activity and was found to be haemo-compatible. However, the n-hexane extract showed moderate and no such activities. Both the extracts exhibited almost zero haemolysis. This seed extracts can be promising for drug development and would achieve economic benefits utilizing this possible source.

\section{References}

Apu AS, Chowdhury FA, Khatun F, Jamaluddin ATM, Pathan AH and Pal A (2013), Phytochemical screening and in vitro evaluation of pharmacological activities of Aphanamixis polystachya (Wall) Parker fruit extracts, Trop. J. Pharm. Res. 12(1): 111-116.

Azam MM, Waris A and Nahar NM (2005), Prospects and potential of fatty acid methyl esters of some non-traditional seed oils for use as biodiesel in India, Biomass Bioenerg. 29(4): 293-302. DOI: org/10.1016/j.biombioe.2005.05.001

Balouiri M, Sadiki M and Ibnsouda SK (2016), Methods for in vitro evaluating antimicrobial activity: A review, $J$. Pharm. Anal. 6(2): 71-79. DOI: org/10.1016/j.jpha.2015.11.005

Bamwal BK (2005), Prospects of biodiesel production from vegetable oils in India, Renew. Sust. Energ. Rev. 9(4): 363-378. DOI: org/10.1016/j.rser.2004.05.007

Bauer AW, Kirby WMM, Sherris JC and Turck M (1966), Antibiotic susceptibility testing by standardized single disc method, Am. J. Clin. Pathol. 45(4): 493-496.

Baümler ER, Carrín ME and Carelli AA (2015), Extraction of sunflower oil using ethanol as solvent, J. Food Eng. 178: 190-197. DOI: org/10.1016/j.j foodeng. 2016.01.020

Bhowmick R, Sarwar MS and Dewan SM (2014), In vivo analgesic, antipyretic, and anti-inflammatory potential in Swiss albino mice and in vitro thrombolytic activity of hydroalcoholic extract from Litsea glutinosa leaves, Biol. Res. 47: 56.
Bhutada PR, Jadhav AJ, Pinjari DV, Nemade PR and Jain RD (2016), Solvent assisted extraction of oil from Moringa oleifera Lam. Seeds, Ind. Crops Prod. 82: 74-80. DOI: org/10.1016/j.indcrop.2015.12.004

Chatterjee A and Kundu AB (1967), Isolation, structure, and stereochemistry of aphanamixin-a new triterpene from Aphanamixis polystachya, Tetrahedron Lett. 16: 1471-1476. DOI: org/10.1016/j.indcrop.2015.12.004

Chowdhury R and Rashid RB (2003), Effect of the crude extracts of Amoora rohituka stem bark on gastrointestinal transit in mice, Indian J. Pharmacol. 35: $304-307$.

Cosmulescu S, Trandafir I and Nour V (2017), Phenolic acids and flavonoids profiles of extracts from edible wild fruits and their antioxidant properties, Int. J. Food Prop. 20(12): 3124-3134. DOI: org/10.1080/ 10942912.2016.1274906

Hossain MM, Biva IJ, Jahangir R and Vhuiyan MMI (2009), Central nervous system depressant and analgesic activity of Aphanamixis polystachya (Wall.) parker leaf extract in mice, Afr. J. Pharm. Pharmacol. 3(5): 282-286. DOI: org/10.5897/AJPP.9000073

Meyer BN, Ferringni NR, Paum JE, Lacobden LB, Nichols DE and McLaughlin JL (1982), Brine Shrimp: a convenient general bioassay for active constituents, Planta Medica. 45: 31-32.

Nabi MN, Hoque SMN and Uddin MS (2009), Prospect of Jatropha Curcas and Pithraj Cultivation in Bangladesh, J. Eng. Technol. 7(1): 01-14.

Osbourne AE (1996), Preformed antimicrobial compounds and plant defense against fungal attack, Plant Cell. 8 (10): 1821-1831. DOI: 10.1105/tpc.8.10.1821

Rabeya T, Jehadin F, Asad MA, Olubunmi OA, Adekunle AE and Islam MS (2020), Alkali and Intensified Heat Treatment of Corn Stalk for Bioethanol Production, Sugar Tech. In press. DOI: org/10.1007/s12649-016-9562-9.

Saeed N, Khan MR and Shabbir M (2012), Antioxidant activity, total phenolic and total flavonoid contents of whole plant extracts Torilis leptophylla L, $B M C$ Complement Altern. Med. 12: 221.

Schaffer SW, Allo S, Harada H, Stroo W, Azuma J and Hamaguchi T (1989), Mechanism Underlying the Membrane-Stabilizing Activity of Taurine. In: 
Taurine and the Heart. Developments in Cardiovascular Medicine, Eds. Iwata H, Lombardini J and Segawa T, vol 93, Springer, Boston, MA.

Sikder MAA, Kuddus MR, Kaisar MA, Kama S and Rashid MA (2010), In vitro membrane stabilizing activity, total phenolic content, free radical scavenging and cytotoxic properties of Aphanamixis polystachya (Wall.), Bangladesh Pharm. J. 13(2): 55-59.

Sitarek P, Merecz-Sadowska A, Kowalczyk T, Wieczfinska J, Zajdel R and Sliwinski T (2020), Potential synergistic action of bioactive compounds from plant extracts against skin infecting microorganisms, Int. J. Mol. Sci. 21: 5105. DOI: org/10.3390/ijms21145105

Sivasankar P, Manivasagan P, Vijayanand P, Sivakumar K, Sugesh S, Poongodi S, Maharani V, Vijayalakshmi S and Balasubramanian T (2013), Antibacterial and brine shrimp lethality effect of marine actinobacterium Streptomyces sp. CAS72 against human pathogenic bacteria, Asian Pac. J. Trop. Dis. 3(4): 286-293. DOI: 10.1016/S2222-1808(13)60071-7

Synytsya A, Monkai J, Bleha R, Macurkova A, Ruml T, Ahn J and Chukeatirote E (2017), Antimicrobial activity of crude extracts prepared from fungal mycelia, Asian Pac. J. Trop. Biomed. 7(3): 257-261. DOI: org/10.1016/ j.apjtb.2016.12.011

Talukder FA and Howse PE (1993), Deterrent and instecidal effects of extracts of pithraj, Aphanamixis. polystachya (Meliaceae), against tribolium castaneum in storage, J. Chem. Ecol. 19(11): 2463-2471.

Taylor JLS, Rabe T, McGaw L, Jager AK and Staden V (2001), Towards the scientific validation of traditional medicinal plants, J. Plant Growth Regul. 34(1): 23-37.

Williams WB, Cuvelier ME and Berset C (1995), Use of a free radical method to evaluate antioxidant activity, Lebensm Wiss Technol. 28(1): 25-30. DOI: org/10.1016/S0023-6438(95)80008-5

Zapata A and Ramirez-Arcos SA (2015), Comparative study of McFarland turbidity standards and the densimat photometer to determine bacterial cell density, Curr. Microbiol. 70: 907-909. 